\title{
Development of Nickel-Added, Iron-Based, Slag-Free, Self-Shielded Metal-Cored Wire
}

\author{
The effects of nickel on the microstructure and wear \\ performance of hardfacing alloys are investigated
}

\author{
BY D. LIU, L. LI, M. WU, W. LONG, P. WEI, N. E. ANDERSON, AND R. KANNAN
}

\begin{abstract}
Previously, an iron-based, slag-free, self-shielded metalcored wire showing a mechanism of porosity prevention was reported in the Welding Journal (Ref. 1). In this paper, a type of iron-based, slag-free, self-shielded metal-cored wire with various nickel contents was developed to fabricate experimental hardfacing alloys. The influence of nickel addition on the microstructure and wear performance was investigated. The results showed the hardfacing alloy with 0.13 wt-\% nickel had a typical hypereutectic microstructure consisting of primary $M_{7}(C, B)_{3}$ carbonitrides with a eutectic of long, bar-like $M_{3}(C, B)$ carbonitrides and martensite. The addition of nickel promoted the formation of austenite dendrites as well as changed the morphology of the eutectic colonies. As the nickel content increased from 2.75 to 3.83 wt-\%, and to $4.64 \mathrm{wt}-\%$, the austenite was observed to develop from a scattered structure to a dendritic structure, and, finally, to a networked structure, respectively. The hardness of the hardfacing alloy was found to decrease from 64.2 HRC with 0.13 wt-\% nickel to 58.2 HRC with 4.64 wt-\% nickel. The morphology of the worn surfaces of the hardfacing alloys showed cracks in the hardfacing alloy with 0.13 wt-\% nickel; a smooth texture for the hardfacing alloy with 2.75 wt-\% nickel; and extensive plastic deformation and grooving as the nickel content was further increased. The optimum wear resistance and cracking resistance of the 2.75 wt-\% nickel hardfacing alloy can be attributed to the presence of a higher fraction of martensite in the matrix, and an optimum amount of retained austenite needed to provide crack resistance.
\end{abstract}

\section{KEYWORDS}

- Nickel • Iron Base • Self-Shielded Metal-Cored Wire - Hardfacing • Wear Resistance

\section{Introduction}

Hardfacing generally refers to methods for overlaying a wear-resistant alloy on the surface of a substrate to resist wear caused by abrasion, corrosion, erosion, and heat, among other operational conditions (Refs. 1, 2). For resist- ing severe wear conditions, iron-based hardfacing alloys have been mainly used owing to their excellent wear resistance and relatively low price (Refs. 3-5). Their excellent wear resistance is derived from the presence of primary $\mathrm{Cr}$ rich carbides in the hypereutectic microstructure (Refs. 6-8).

A variety of methods are available to fabricate this hardfacing alloy, including welding, where a welding wire is deposited on the contacting surface to produce an alloy having a high wear resistance (Refs. 9, 10). The welding wire may be either a solid wire or a metal-cored wire (Ref. 11). Because the iron-based hardfacing alloy with a hypereutectic microstructure is difficult to plastically form, the solid wire must be fabricated by the casting method (Ref. 12). In contrast, the metal-cored wire is conveniently employed to obtain the iron-based hardfacing alloy with a hypereutectic microstructure (Refs. 13-15).

However, a high fraction of $\mathrm{Cr}$-rich carbides is difficult to obtain in hypereutectic microstructures of these alloys, mainly due to a limited powder filling coefficient for the metal-cored wire. The traditional metal-cored wire is comprised of a metal sheath filled with a mixture of alloy and mineral powders. The alloy powders contribute to the alloying of the weld metal. The mineral powders, such as marble, rutile, and fluorite, are mainly to form gaseous and slag protections for the droplet and molten pool (Ref. 16). The addition of mineral powders usually undermines the alloy-filling coefficient because a lesser amount of metal powders can be compacted.

To increase the powder-filling coefficient of flux-cored wires, we have developed a new type of iron-based, slag-free, self-shielded metal-cored wire that comprises a metal sheath filled almost entirely with powdered metal alloys (Refs. 8, 9, 13, 16, 17). The elements W (Ref. 8), B (Ref. 9), Ti (Ref. 13), and $\mathrm{Nb}$ (Ref. 17) have been added into the cored wire to improve the fraction of carbides, which improves the wear resistance of iron-based hardfacing alloys. However, the wear resistance behavior not only depends on the chemical composition, size, shape, and distribution of carbides, but also on the characteristics of the matrix (Refs. 18, 19).

Yamamoto et al. (Ref. 20) reported that nickel content and its precipitation region shifts to the low- $\mathrm{C}$, high- $\mathrm{Cr}$ 
Table 1 - Chemical Composition of the H08A Steel

\begin{tabular}{cl} 
Elements & wt- $\%$ \\
\hline $\mathrm{C}$ & $\leq 0.10$ \\
$\mathrm{Si}$ & $\leq 0.03$ \\
$\mathrm{Mn}$ & $0.30-0.55$ \\
$\mathrm{P}$ & $\leq 0.030$ \\
$\mathrm{~S}$ & $\leq 0.030$
\end{tabular}

region as the nickel content increases in a high-chromium cast iron. Lin et al. (Ref. 21) reported that nickel addition decreases the hardness of eutectic colonies of microstructure of $\mathrm{Cr}-\mathrm{Fe}-\mathrm{C}$ hardfacing alloys. Balachandran et al. (Ref. 22) reported that low nickel containing (0.62 wt-\%) austempered cast iron gives higher wear resistance. The probable reason for this could be that higher nickel tends to stabilize the austenite, which may improve the toughness of the matrix. Previous research seems to indicate that nickel has important but complex effects on the matrix of hardfacing alloys.

In this study, varying contents of nickel were added into an experimental iron-based, self-shielded cored wire. The effects of nickel on the microstructure and wear performance of hardfacing alloys were investigated.

\section{Experimental Procedures}

The flux-cored wires were fabricated by using a strip of lowcarbon steel H08A with a size of 16 (width) $\times 0.3 \mathrm{~mm}$ (thickness), which was formed into a U-shaped cross section, and a metered amount of alloying powder was dispensed in the Ushaped cross section. The U-shaped strip was passed through closing rollers to form a circular cross section, and the tube was then pulled through drawing dies to reduce the diameters of the wire to a desired size and compress the powder core. Table 1 shows the chemical composition of the H08A strip steel. Each wire had a diameter of $2.4 \mathrm{~mm}$. The filling coefficient was 53 wt-\%.

Table 2 displays the different powders added into the metal-cored wires. To investigate the effects of nickel on the microstructure and wear performance of iron-based, self-shielded, metal-cored hardfacing alloys, the mass fraction of pure nickel added into the cored wire was $0,5,9$, and 12 wt-\%, respectively.

Q235 steel plates (with 0.16 wt-\% carbon and 0.5 wt-\% manganese) with dimensions of $200 \times 120 \times 20 \mathrm{~mm}$ were used as hardfacing substrates. To eliminate the effects of dilution, the hardfacing alloy was deposited for five layers on the substrate, and the top layer was extracted for characterization. Table 3 shows the welding parameters.

The specimens with dimensions of $10 \times 10 \times 8 \mathrm{~mm}$ were cut out from the top layers of the hardfacing alloys by wire-
Table 2 - Chemical Composition of the Metal Core

\begin{tabular}{cl} 
Powder & wt- $\%$ \\
\hline High-carbon ferrochrome (65Cr, 9C) & $50-70$ \\
Electrolytic manganese (pure) & $2-8$ \\
Ferrosilicon (75Si) & $3-7$ \\
Ferroboron (20B) & $8-18$ \\
Graphite (pure) & $2-6$ \\
Stabilizing agent & $2-10$ \\
Iron (pure) & Balance
\end{tabular}

Table 3 - Welding Parameters

Parameter

Welding current

390-420 A

Arc voltage

Electrode polarity

Welding speed

Electrode extension

$36-38$

Positive

$0.3 \mathrm{~m} / \mathrm{min}^{-1}$

$26-30 \mathrm{~mm}$

electrical discharge machining. Table 4 shows the chemical compositions of the hardfacing alloys containing different nickel levels. The composition was determined using inductively coupled plasma optical emission spectroscopy (ICP-OES) except for carbon, which was tested using combustion analysis. For microstructural studies, optical microscopy (OM) and scanning electron microscopy (SEM) were conducted on the specimens etched with a mixture of 3-mL, $68 \%$ nitric acid; $15-$ $\mathrm{mL}, 38 \%$ hydrochloric acid; 3-g ferric chloride; and 50-mL water. Electron backscattered diffraction (EBSD) analysis on the hardfacing alloys was conducted on a Zeiss Sigma field-emission scanning electron microscope (FESEM) equipped with an Oxford AZtec EBSD system. The operating conditions of the SEM were $20-\mathrm{kV}$ accelerating voltage, $60-\mu \mathrm{m}$ objective aperture, and $0.35-\mu \mathrm{m}$ step size. The EBSD data was postprocessed with the Channel 5 software package. X-ray diffraction (XRD) analysis was carried out with a Rigaku Ultima IV diffractome-

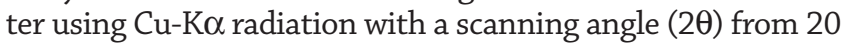
to 100 deg. Rietveld refinement of the XRD data to determine phase fraction was performed using the open source software Profex with BGMN (Ref. 23). The bulk hardness studies of the hardfacing alloys with various nickel concentrations were conducted using a Rockwell hardness tester. Five readings were taken in close proximity, and the mean values were reported.

The wear performance was evaluated using a HT-500 pin-on-disk tribometer with the test material in conformal contact against a ball. The parameters of the wear test are shown in Table 5. The friction coefficient was obtained from the ratio of the friction force to the applied load. An electronic balance (0.1-mg accuracy) was used to weigh the specimens before and after abrading. Three test specimens were made

Table 4-Chemical Compositions (wt-\%) of the Hardfacing Alloys Containing Different Nickel Additions (ICP-OES and Combustion Analysis)

\begin{tabular}{cccccccc} 
Ni (Nominal) & $\mathrm{Ni}$ & $\mathrm{C}$ & $\mathrm{B}$ & $\mathrm{Cr}$ & $\mathrm{Mn}$ & $\mathrm{Si}$ \\
\hline 0 & 0.13 & 3.33 & 1.41 & 17.6 & 2.78 & 0.93 & 75.2 \\
5 & 2.75 & 3.18 & 1.39 & 16.9 & 2.60 & 7.06 & 74.3 \\
9 & 3.83 & 3.10 & 1.34 & 16.2 & 2.57 & 0.98 & 74.4 \\
12 & 4.64 & 2.97 & 1.26 & 15.4 & 2.45 & 0.95 & 74.0 \\
\hline
\end{tabular}




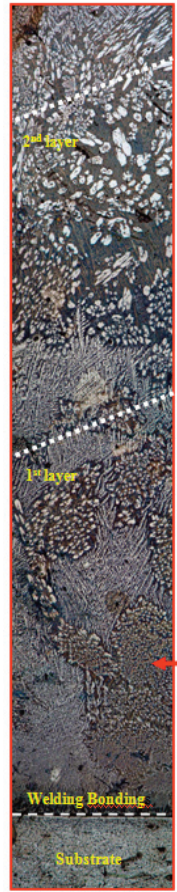

B

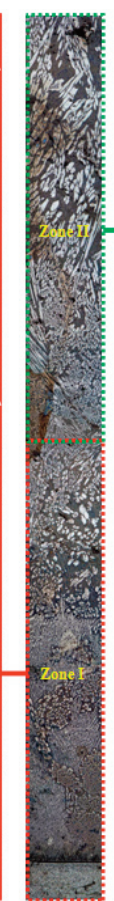

A

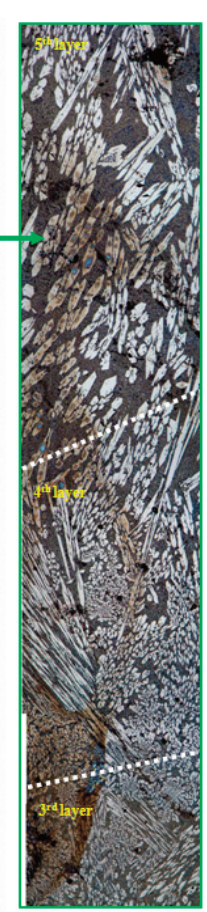

C
Fig. 1-Cross-section microstructure of the hardfacing alloy.

from each sample and tested separately. An average of the three numbers was calculated and recorded. The wear tracks were observed under the SEM. Thermodynamic driving force calculations were performed using the ThermoCalc TCFE6 database (Ref. 24).

\section{Results}

\section{Effect of Nickel on the Microstructure of the Hardfacing Alloy}

Figure 1 shows the typical cross-section images of the hardfacing alloy. Figure $1 \mathrm{~A}$ shows that dilution with the low-carbon substrate material exhibited a significant influence on the microstructure of the hardfacing alloy. Figure $1 \mathrm{~B}$ shows a metallurgical bonding between the first layer and the substrate. The $\mathrm{Fe}-\mathrm{Cr}$ dendrites and the small-sized carbides were precipitated in the hardfacing alloy of the first layer. The carbides were distributed nonuniformly. It can be seen in Fig. $1 \mathrm{~B}$ and $C$ that the size and the quantity of carbides increased, and the morphology of carbides transitioned from blade-like to rod-like with the

Table 5 - Wear Test Parameters

\section{Parameter}

$\begin{array}{cc}\text { Counter face material } & \text { AISI T2 high-speed tool steel (HRC 62) } \\ \text { Load }(\mathrm{N}) & 10.3 \\ \text { Velocity }(\mathrm{rpm}) & 560 \\ \text { Wear time (min) } & 20 \\ \text { Diameters of the ball }(\mathrm{mm}) & 3 \\ \text { Radius of wear track }(\mathrm{mm}) & 4\end{array}$

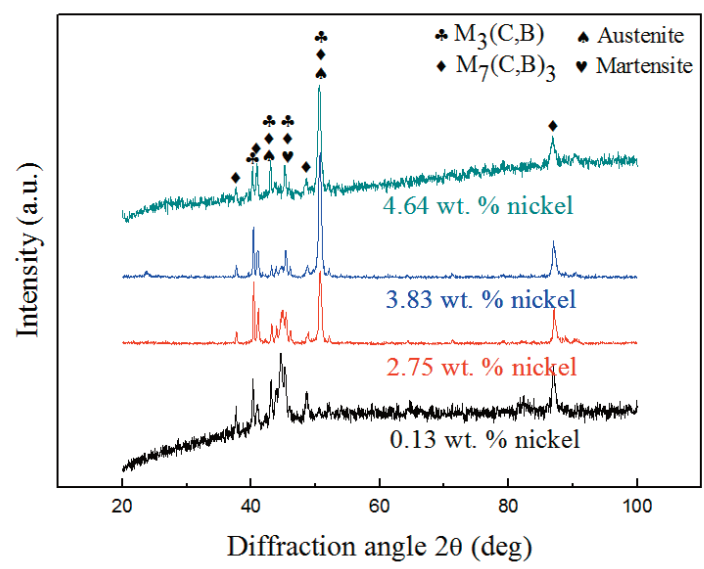

Fig. 2 - The XRD of hardfacing alloys with different nickel levels.

increased number of deposited layers. This indicates the growth direction of the carbides changed, since blades and rods were merely appearances of different cross sections relative to the direction of the rods (Refs. 25, 26). Moreover, there was a dispersed uniform distribution of carbides in the hardfacing alloy for the fifth layer.

Figure 2 shows the XRD patterns of the hardfacing alloys. The phases in the hardfacing alloy with $0.13 \mathrm{wt}-\%$ nickel were mainly composed of $\mathrm{M}_{7}(\mathrm{C}, \mathrm{B})_{3}, \mathrm{M}_{3}(\mathrm{C}, \mathrm{B}),(\mathrm{M}=\mathrm{Cr}, \mathrm{Fe})$ martensite, and traces of retained austenite. The addition of different nickel contents changes the phase compositions, and, most significantly, enhances the austenite phase. The fraction of different phases in the hardfacing alloys calculated using Rietveld refinement were tabulated in Table 6 . It can be seen that with the increase in nickel content of the hardfacing alloy, the fraction of retained austenite increased from $4.5 \%$ in the alloy with 0.17 wt-\% nickel to $31 \%$ in the hardfacing alloy with 4.64 wt-\% nickel. The hardfacing alloy with $2.75 \mathrm{wt}-\%$ nickel seemed to have the highest fraction of martensite.

Figure 3 shows the microstructures of the hardfacing alloys with different nickel levels. A typical hypereutectic microstructure consists of primary hexagonal-shaped $\mathrm{M}_{7}(\mathrm{C}, \mathrm{B})_{3}$ and eutectic colonies of $\mathrm{M}_{3}(C, B)$ plus martensite and residual austenite in the hardfacing alloy with $0.13 \mathrm{wt}-\%$ nickel, which was verified by XRD analysis. Solidification of the hardfacing alloy with $0.13 \mathrm{wt}-\%$ nickel began with the nucleation of primary $\mathrm{M}_{7}(\mathrm{C}, \mathrm{B})_{3}$ carbides from the liquid at approximately $1149^{\circ} \mathrm{C}$ (Ref. 13). The formation of primary $\mathrm{M}_{7}(\mathrm{C}, \mathrm{B})_{3}$ carbides was followed by the eutectic reaction at which eutectic $\mathrm{M}_{3}(\mathrm{C}, \mathrm{B})$ carbides and eutectic austenite were simultaneously formed. With increasing the amount of nickel (Fig. 3C, D), the austenite dendrite appeared and increased.

Figure 4 shows the morphology of austenite of the hardfacing alloys with different nickel levels. The austenite dendrite was not observed in the hardfacing alloy with 0.13 wt-\% nickel - Fig. 4A. Compared to the hardfacing alloy with $0.13 \mathrm{wt}-\%$ nickel, the addition of nickel led to the change of the size and morphology of the austenite phase, as shown in Fig. 4B-D. It can be said that the size of the austenite phase for nickel-containing hardfacing alloy was 

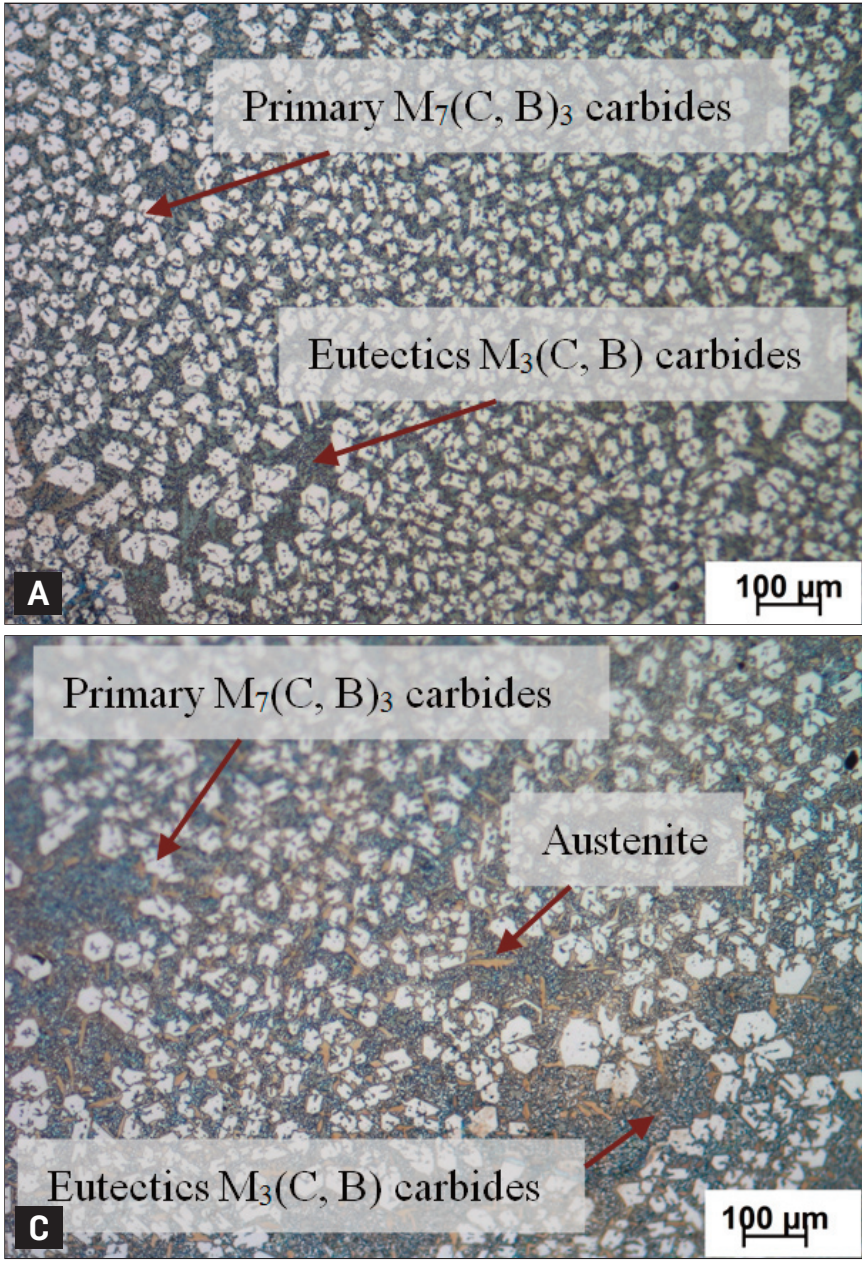
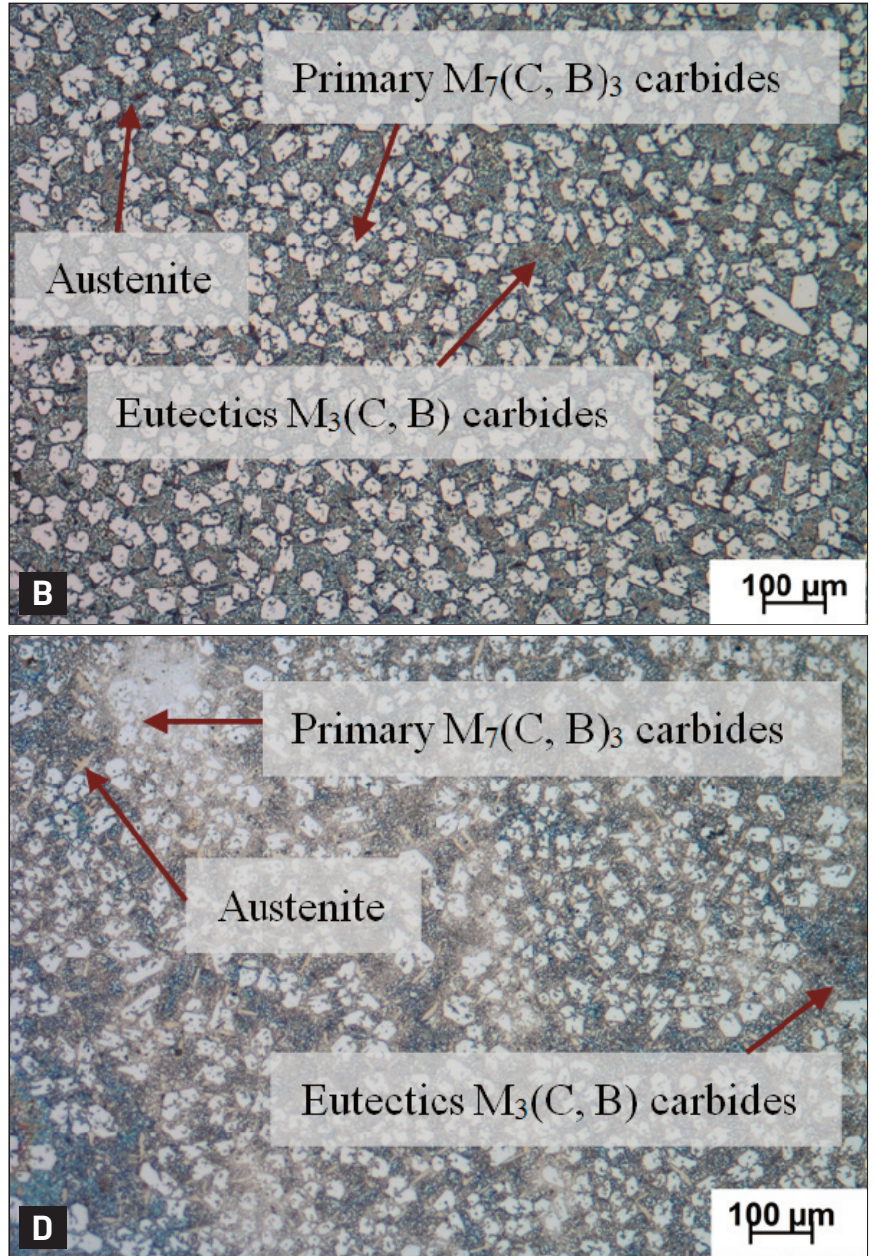

Fig. $3-$ Microstructures of the hardfacing alloys with different nickel levels: $A-0.13$ wt-\% nickel; $B-2.75$ wt-\% nickel; $C-3.83$ wt-\% nickel; D -4.64 wt-\% nickel.

bigger than that of the hardfacing alloy with 0.13 wt-\% nickel. The size of the austenite phase was increased gradually with increasing the nickel from 2.75 to 4.64 wt-\%.

Figure 5 shows the SEM images of hardfacing alloys with various nickel levels. In Fig. 5A and B, there is a typical hypereutectic structure in the alloy with $0.13 \mathrm{wt}-\%$ nickel. In the solidification process, the primary $\mathrm{M}_{7}(\mathrm{C}, \mathrm{B})_{3}$ carbides were separated from the high-temperature liquids, followed by the eutectic colonies consisting of long, bar-like eutectic carbides plus martensite and the residual austenite matrix. In the alloy with 2.75 wt-\% nickel, the eutectic carbides were the scattered web form (Fig. 5C, D). In the alloy with 3.83 wt-\% nickel, the austenite dendrites were obvious (Fig. 5E, F), whereas in the alloy with $4.64 \mathrm{wt}-\%$ nickel the austenite dendrites were consistently present (Fig. 5G, H).

Figure 6 shows the distribution of carbon, boron, chromi- um, manganese, silicon, and iron in the alloy with $0.13 \mathrm{wt}-\%$ nickel examined by EDS mapping analysis and its EBSD phase maps. In Fig. 6A-G, the dark precipitations were rich in chromium, carbon, boron, and manganese, which shows that those phases are $\mathrm{Cr}$-rich carbides. In addition, carbon, boron, manganese, silicon, chromium, and iron were detected in the finer eutectic precipitations with grey color, while silicon and iron were both detected mainly in the matrix. The phase maps confirm that the primary carbide is $M_{7}(C, B)_{3}$ carbide, the eutectic carbide is $M_{3}(C, B)$ carbide, and martensite $(B C C)$ is formed around these carbides. Retained austenite was not detected in this sample likely because of the coarser step size used during the EBSD data acquisition. The phase fraction of carbides and martensite determined using EBSD were 91.51 and $7.22 \%$, respectively, which matched the phase fraction measured using XRD (Table 6). Ni is known not to form car-

Table 6 - Fraction of Phases Calculated by Rietveld Refinement of the Raw XRD Data in Fig. 2

\begin{tabular}{|c|c|c|c|c|c|c|c|c|}
\hline $\mathrm{Ni}$ & C & B & $\mathrm{Cr}$ & $M n$ & $\mathrm{Si}$ & $\mathrm{f}_{\gamma}(\%)$ & $f_{\alpha},(\%)$ & $f_{\text {carbides }}(\%)$ \\
\hline 0.13 & 3.33 & 1.41 & 17.6 & 2.78 & 0.93 & 4.51 & 4.80 & 90.69 \\
\hline 2.75 & 3.18 & 1.39 & 16.9 & 2.60 & 1.06 & 6.20 & 17.30 & 76.50 \\
\hline 3.83 & 3.10 & 1.34 & 16.2 & 2.57 & 0.98 & 8.90 & 4.80 & 86.30 \\
\hline 4.64 & 2.97 & 1.26 & 15.4 & 2.45 & 0.95 & 30.80 & 0 & 69.20 \\
\hline
\end{tabular}



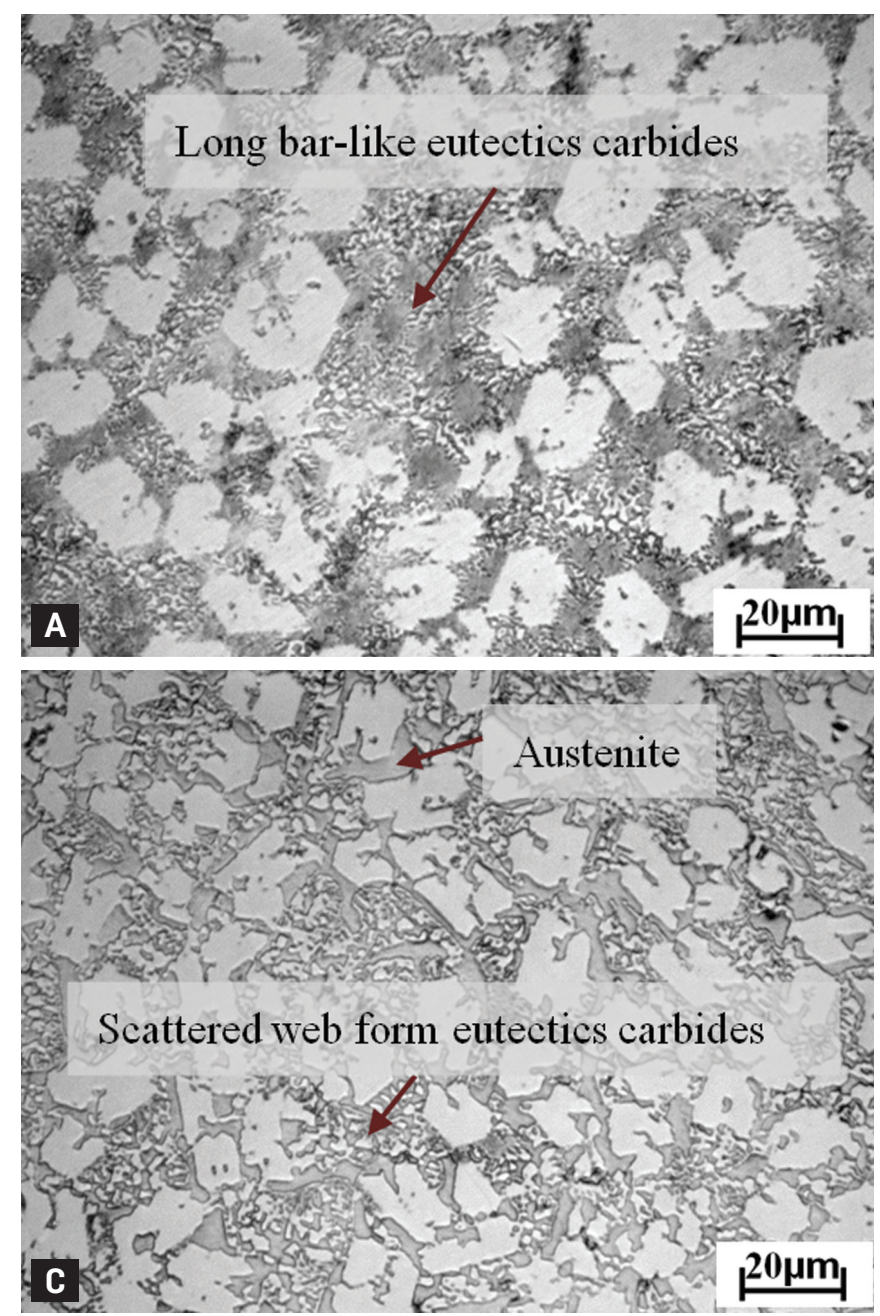
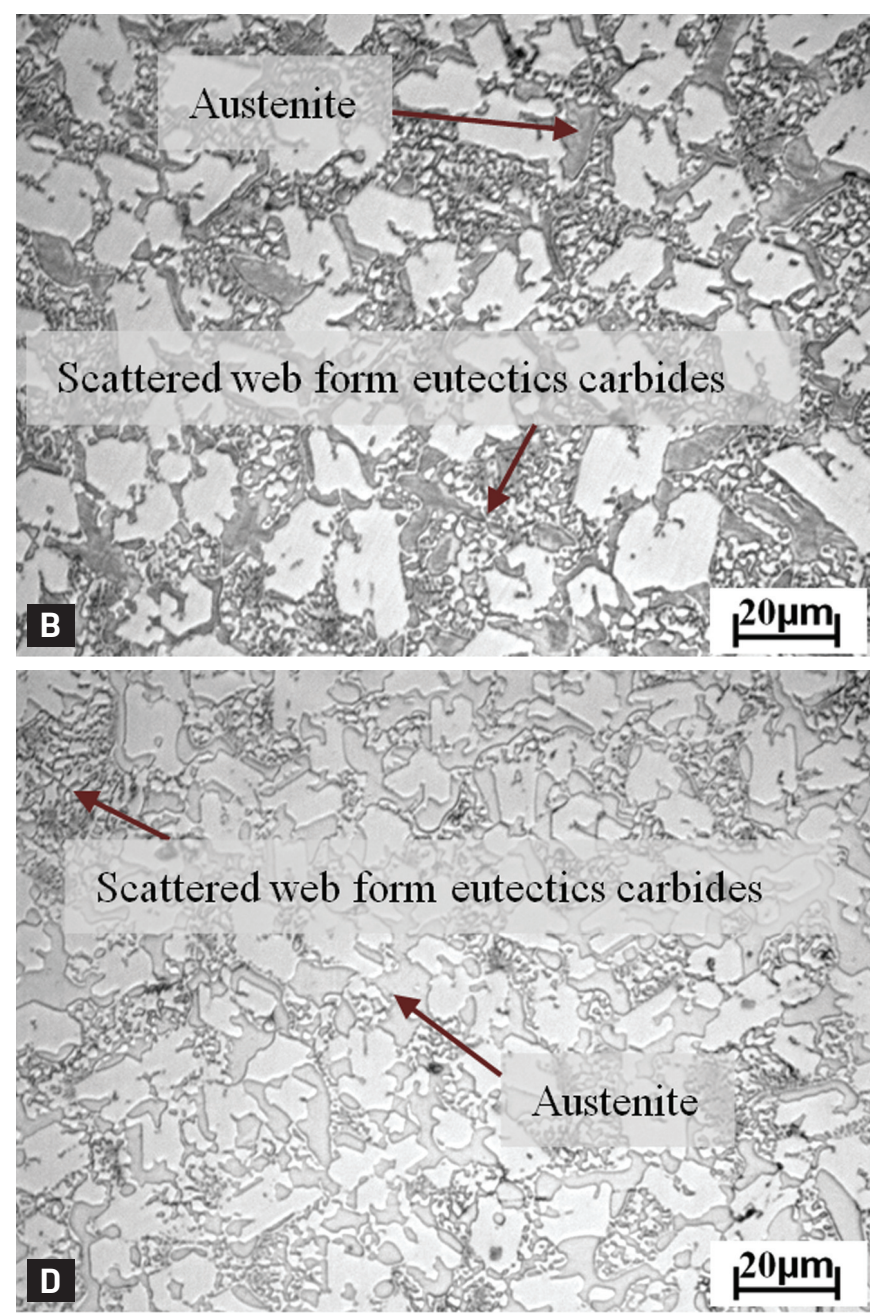

Fig. 4 - Austenite morphology of the hardfacing alloys with different nickel levels: $A-0.13$ wt-\% nickel; B - 2.75 wt-\% nickel; C 3.83 wt-\% nickel; $D-4.64$ wt-\% nickel.

bides itself. Although the fraction of carbides should continuously decrease with the increasing $\mathrm{Ni}$, the reason for the increase in the experimentally measured carbide fraction in the 3.83 wt-\% Ni sample (Table 6) may be related to the significant decrease of martensite, but this is not confirmed at this moment. Other minor phases were $\mathrm{M}_{23}(\mathrm{C}, \mathrm{B})_{6}, \mathrm{Cr}_{3} \mathrm{~B}_{4}, \mathrm{CrB}$, and $\mathrm{Al}_{2} \mathrm{O}_{3}$. The $\mathrm{Al}_{2} \mathrm{O}_{3}$ is a deoxidation product of the chemical metallurgical process - Fig. $6 \mathrm{H}$.

Figure 7A-H shows the distribution of nickel, carbon, boron, chromium, manganese, silicon, and iron in the alloy with 4.64 wt-\% nickel addition examined by EDS mapping analysis. The coarse gray precipitations were rich in chromium, carbon, boron, and manganese, which show that those phases were primary $\mathrm{Cr}$-rich carbides. In addition, carbon, boron, manganese, silicon, chromium, and iron was detected in the finer eutectic precipitations with gray color while silicon, iron, and nickel were detected mainly in the matrix. Figure 7I shows the reconstructed EBSD phase maps of the hardfacing alloy with 4.64 wt-\% nickel addition. The phase maps confirm that the primary carbide is $\mathrm{M}_{7}(\mathrm{C}, \mathrm{B})_{3}$ carbide, the eutectic carbide is $\mathrm{M}_{3}(C, B)$ carbide, and austenite (FCC) is formed around these carbides. Martensite was not detected in this sample probably because of the coarser step size used during the EBSD data ac- quisition. The phase fraction of carbides and retained austenite determined using EBSD were 67 and 32\%, respectively, which matched the phase fraction measured using XRD (Table 6).

\section{Effect of Nickel on the Hardness and Wear Resistance of the Hardfacing Alloy}

Figure 8 shows the change of hardness and wear loss as the content of nickel is increased in the hardfacing alloy. It can be seen that with the increase in nickel content in the hardfacing alloy, the hardness decreased from 64.2 HRC for the hardfacing alloy with $0.13 \mathrm{wt}-\%$ nickel to $58.2 \mathrm{HRC}$ for the hardfacing alloy with 4.64 wt-\% nickel. On the other hand, the wear loss of the hardfacing alloy decreased with increasing the content of nickel to 2.75 wt-\%, and then increased.

Figure 9 shows the coefficients of friction of hardfacing alloys with different nickel levels. At the initial run-in distance, the contact surface of the hardfacing alloy and counterpart AISI T2 high-speed tool steel ball was observed to be scraggly at a micro level; due to local surface roughness, only small local areas were contacted, and as a result, deformation occurred (Ref. 20). After the run-in period, it transitioned into the steady state stage, and the coefficients of friction became rela- 

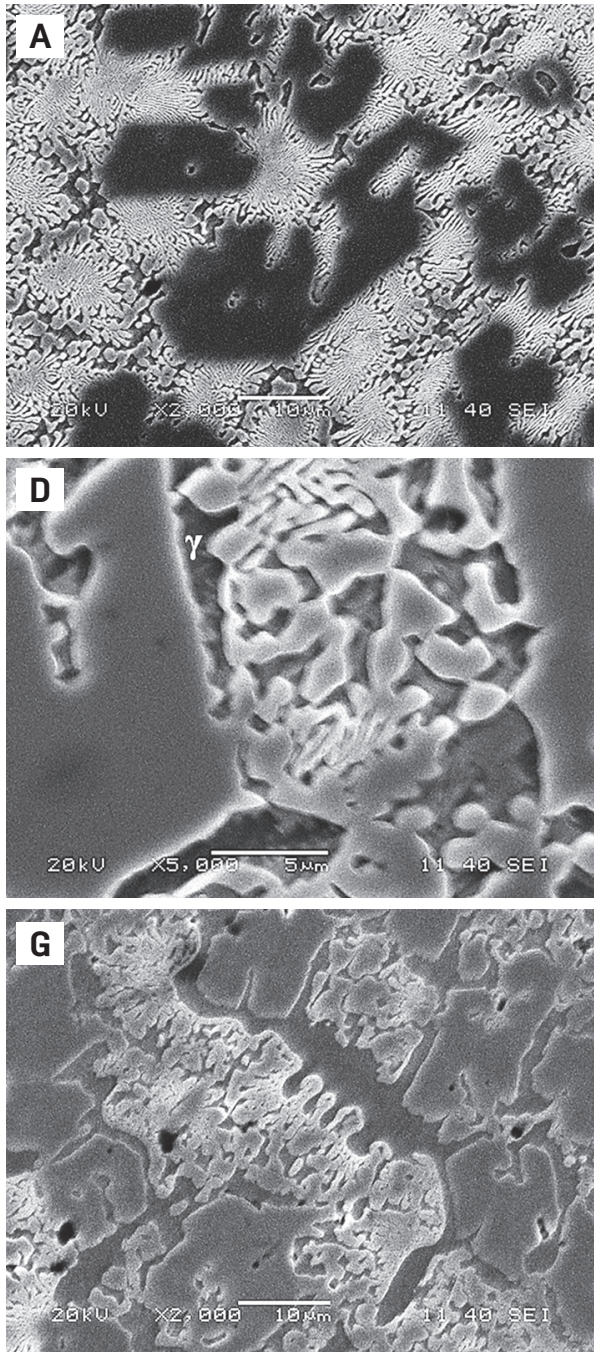
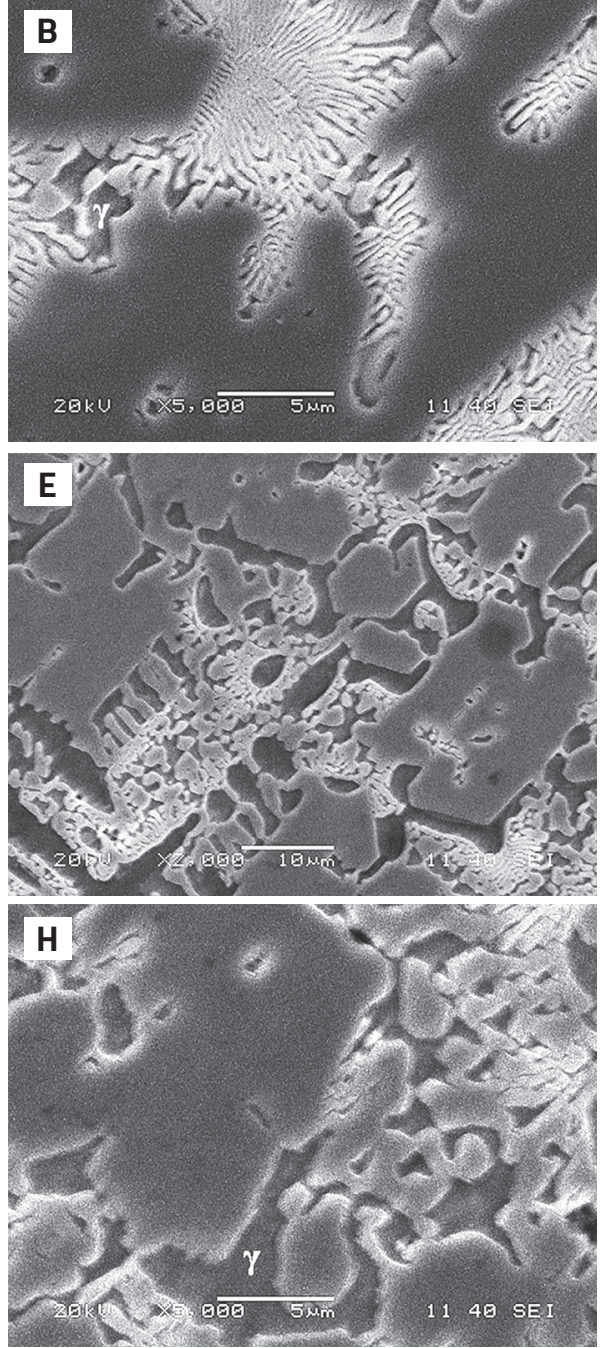

Fig. 5 - SEM image of hardfacing alloys with different nickel levels: $A-0.13$ wt-\% nickel; $B-$ magnification of $A ; C-2.75$ wt-\% nickel; $D-$ magnification of $C$; $E-3.83$ wt-\% nickel; F - magnification of E; G - 4.64 wt-\% nickel; $H$ - magnification of G.
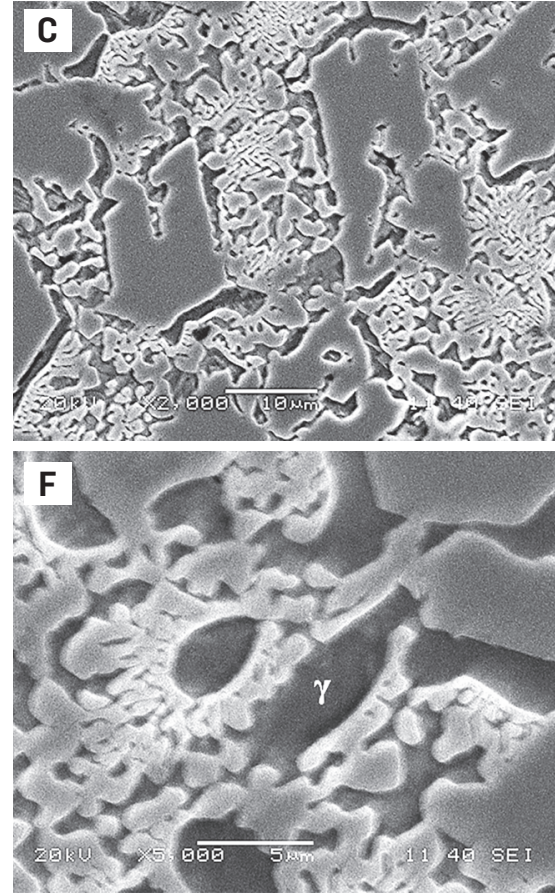

additions in Fig. 10, it can be seen that the hardfacing alloy with $2.75 \mathrm{wt}-\%$ nickel had the optimum wear performance. The phase fraction results from XRD (Table 6) shows that the hardfacing alloy with $2.75 \mathrm{wt}-\%$ nickel had the highest fraction of martensite. It has been widely reported that a martensitic matrix provides a much greater wear resistance than a completely austenitic matrix. Thus, the presence of martensite in the matrix is the likely reason for the lowest wear loss for the hardfacing alloy with 2.75 wt-\% nickel. To understand the reason for the highest fraction of martensite in the hard-

tively steady. The final stable coefficient of friction of the hardfacing alloy with 2.75 wt-\% nickel was the lowest, followed by that of the hardfacing alloy with 0.13 wt-\% nickel, the hardfacing alloy with $3.83 \mathrm{wt}-\%$ nickel, and finally the hardfacing alloy with $4.64 \mathrm{wt}-\%$ nickel.

Figure 10 shows the worn surfaces of hardfacing alloys with different nickel levels. It can be seen in Fig. 10A that the worn surface of the hardfacing alloy with 0.13 wt-\% nickel had several cracks. The worn surface of the hardfacing alloy with 2.75 wt-\% nickel almost retained the smooth texture - Fig. 10B. When the nickel concentration exceeded $2.75 \mathrm{wt}-\%$, the obvious decrease in the hardness was owed to the formation of a larger fraction of the austenite phase in the matrix, and thus the worn surface of the hardfacing alloy was easily plastically deformed and grooved - Fig. 10C, D.

\section{Discussion}

From the wear-test results presented in Fig. 8, the friction coefficient results presented in Fig. 9, and the SEM images of the worn surface of the hardfacing alloys with different nickel facing alloy with $2.75 \mathrm{wt}-\%$ nickel, thermodynamic driving force calculations were performed for all of the hardfacing alloys in this study. The driving force calculations were performed by setting the BCC phase as a dormant phase, thereby supersaturating the high-temperature austenite.

Figure 11 shows the driving force for the formation of martensite from austenite for all the hardfacing alloys. It should be noted that ThermoCalc expressed the driving force per mole of the product phase as the decrease in Gibb's free energy for the formation in the product phase from the supersaturated parent phase $(\Delta \mathrm{Gm})$. Thus, a negative driving force predicted by ThermoCalc implies that the reaction raises the Gibb's free energy of the system, and the reaction will not take place. In Fig. 11, it can be seen that the driving force for the formation of martensite from austenite is positive for the hardfacing alloys with $0.13,2.75$, and 3.83 wt-\% nickel, and hence martensitic transformation is possible in these hardfacing alloys. The driving force for the formation of martensite is negative for the hardfacing alloy with 4.64 wt-\% nickel, and hence martensitic transformation is not possible for this hardfacing alloy, which goes along with the 

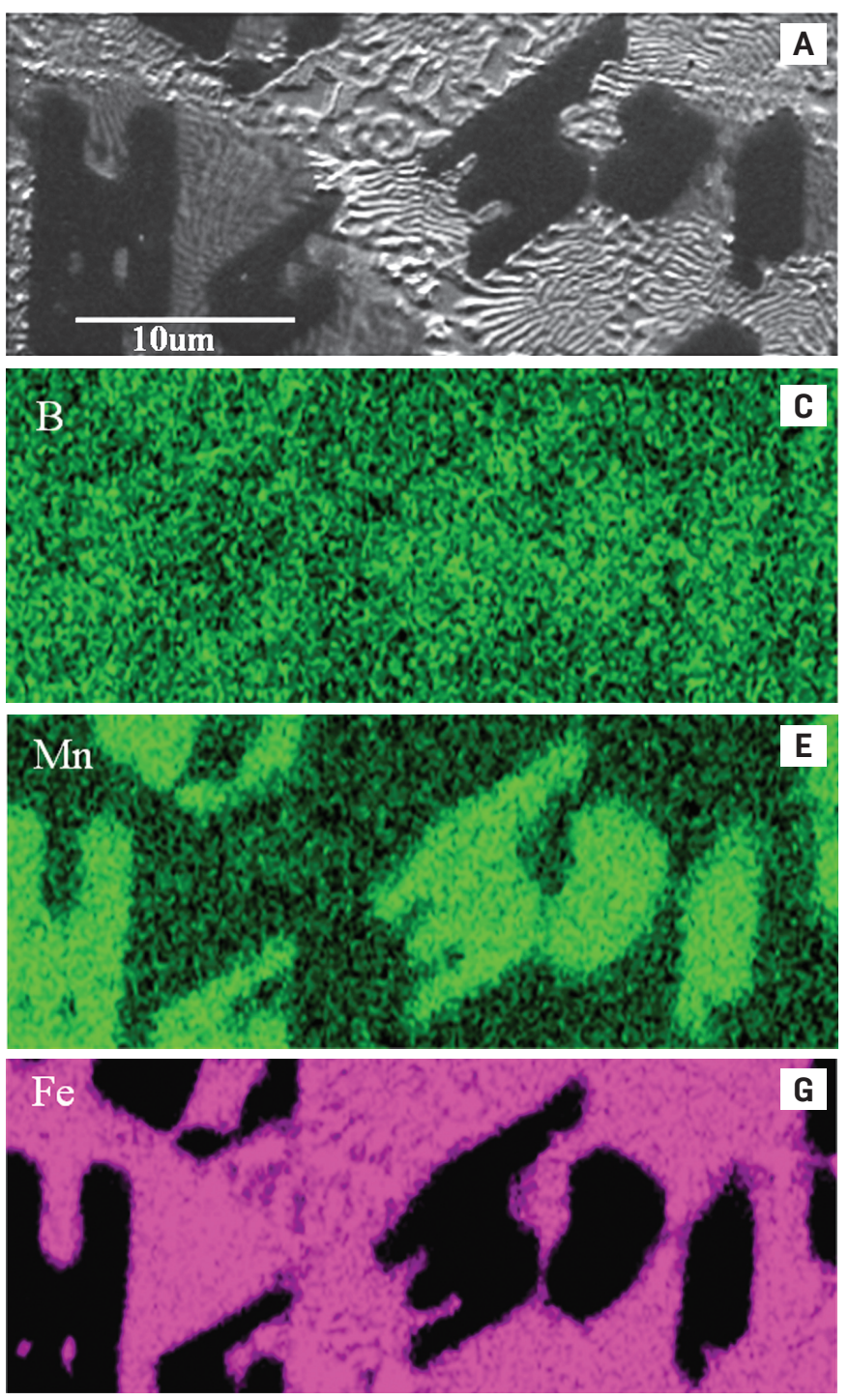
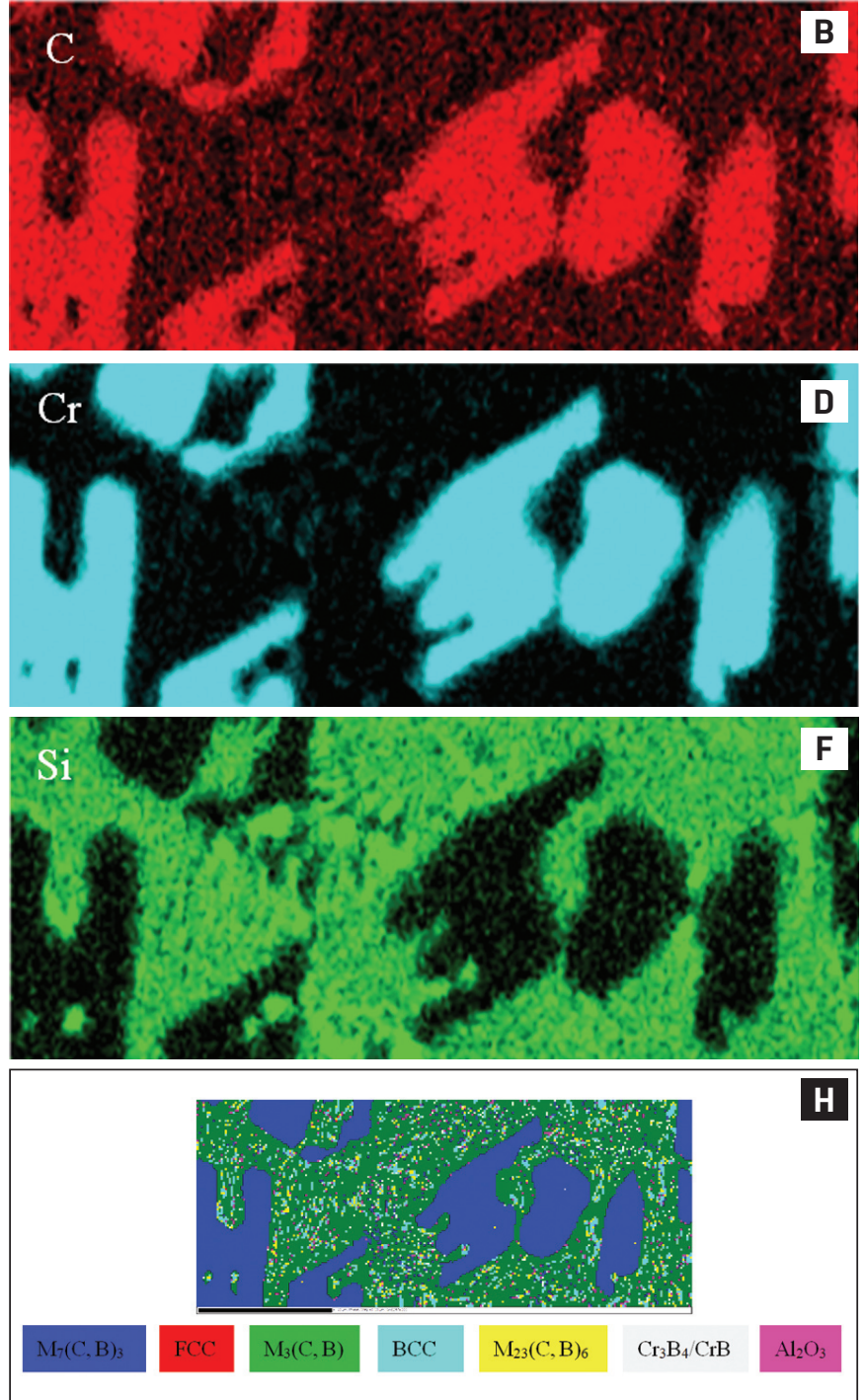

Fig. 6 - Combined EDX and EBSD mapping for the hardfacing alloy with 0.13 wt-\% nickel: A - Secondary electron SEM image; B-G - elemental distribution of $\mathrm{C}, \mathrm{B}, \mathrm{Cr}, \mathrm{Mn}$, Si, and Fe, respectively; $\mathrm{H}-\mathrm{EBSD}$ phase identification map.

$0 \%$ martensite fraction calculated from XRD in Table 6.

The driving force for the formation of martensite is highest for the hardfacing alloy with $2.75 \mathrm{wt}-\%$ nickel; thus, thermodynamically, the hardfacing alloy with $2.75 \mathrm{wt}-\%$ nickel will have the highest fraction of martensite, which goes along with the experimental martensite fraction calculated from XRD in Table 6. The thermodynamic driving force calculations provide an explanation as to why the hardfacing alloy with $2.75 \mathrm{wt}-\%$ nickel has the highest fraction of martensite. The wear resistance is not simply related to the hardness of the hardfacing alloy; it is determined by the carbides and matrix structure of the hardfacing alloy (Ref. 18). Therefore, the hardfacing alloy with 0.13 wt-\% nickel, despite having the highest hardness (Fig. 9), displays lower wear resistance than that of the hardfacing alloy with $2.75 \mathrm{wt}-\%$ nickel addition. Compared to the wear resistance of the hardfacing alloy with $0.13 \mathrm{wt}-\%$ nickel, the better wear resistance of the hardfacing alloy with $2.75 \mathrm{wt}$ $\%$ nickel addition can thus be attributed to the presence of a higher fraction of martensite in the matrix. The deterioration in wear resistance with the increase in nickel content in the hardfacing alloy with more than $2.75 \mathrm{wt}-\%$ can be attributed to the increase in fraction of austenite, which significantly reduces the hardness of the matrix - Fig. 9.

Comparing the worn surfaces of the different hardfacing alloys (Fig. 10), the presence of cracks in the hardfacing alloy with $0.13 \mathrm{wt}-\%$ nickel can be attributed to the brittle microstructure of the hardfacing alloy, which is primarily composed of $\mathrm{M}_{7}(\mathrm{C}, \mathrm{B})_{3}$ and $\mathrm{M}_{3}(\mathrm{C}, \mathrm{B})$ carbides (Table 6$)$. Moreover, when the nickel addition is $2.75 \mathrm{wt}-\%$, the fraction of austenite increases (Table 6), which is distributed in the matrix of the microstructure and blocks the cracks growing from the surface of the primary carbides into the matrix. The solid solution of nickel in the matrix also enhances the strength and toughness of the matrix to fasten the hard, primary carbides in place. When the nickel content in the hardfacing alloys is further increased, austenite is stabilized (Table 6), and the surface of the hardfacing alloy is easily plastically deformed and grooved Fig. 10C, D.

For these reasons, it can be concluded that the hardfacing alloy with $2.75 \mathrm{wt}-\%$ nickel has the optimum wear resistance 

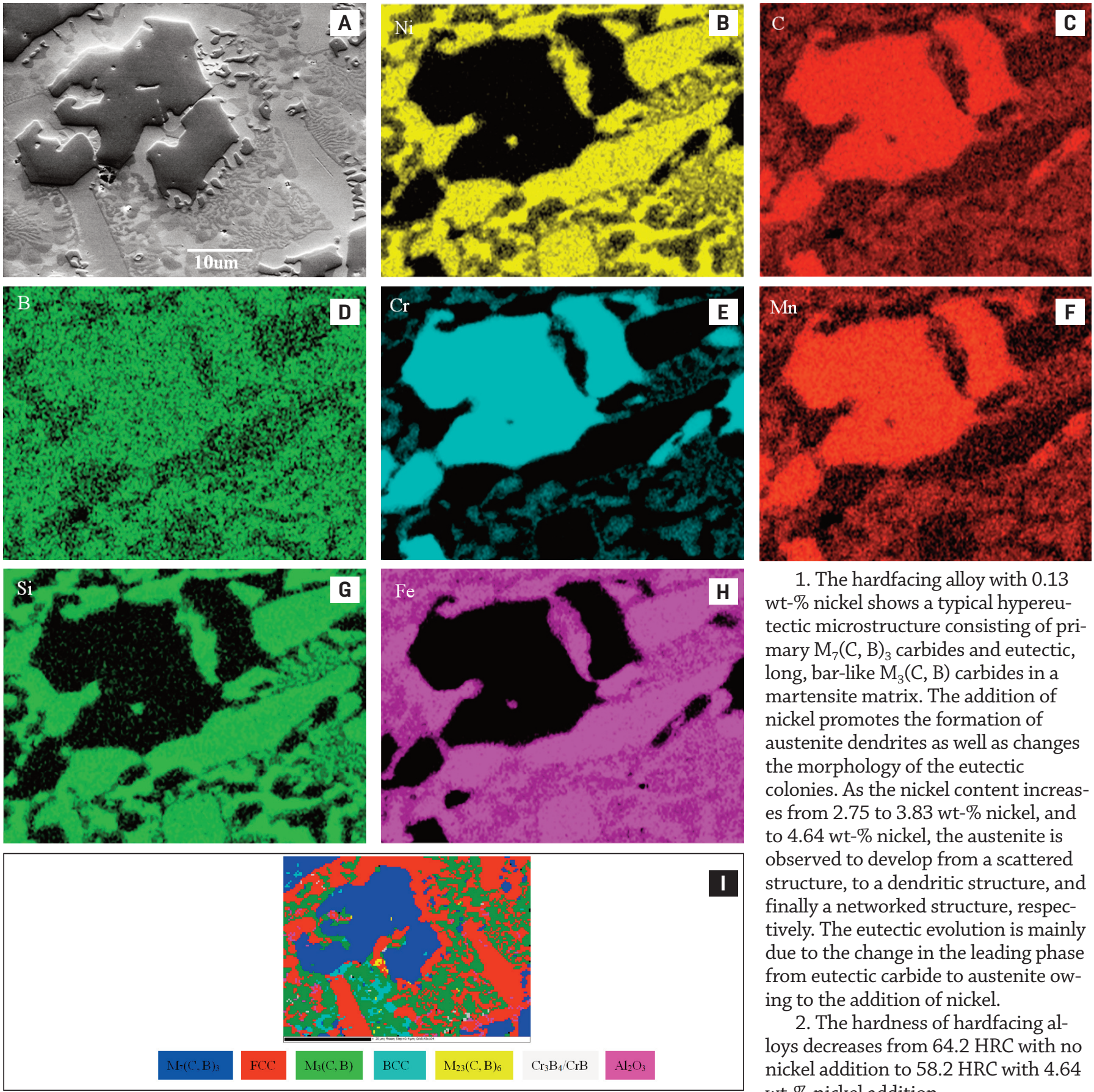

Fig. 7-Combined EDX and EBSD mapping for the hardfacing alloy with $4.64 \mathrm{wt}-\% \mathrm{Ni}$ : A - Secondary electron SEM image; B-H - elemental distribution of $\mathrm{Ni}, \mathrm{C}, \mathrm{B}, \mathrm{Cr}, \mathrm{Mn}, \mathrm{Si}$, and $\mathrm{Fe}$, respectively; I - EBSD phase identification map.

and cracking resistance owing to the presence of a higher fraction of martensite in the matrix as well as the optimum amount of retained austenite needed to provide the crack resistance without overly softening the hardfacing.

\section{Conclusions}

A new type of slag-free, self-shielded metal-cored wire with nickel addition has been developed. Based on the results, the following conclusions can be drawn:
1. The hardfacing alloy with 0.13 wt-\% nickel shows a typical hypereutectic microstructure consisting of primary $\mathrm{M}_{7}(\mathrm{C}, \mathrm{B})_{3}$ carbides and eutectic, long, bar-like $\mathrm{M}_{3}(C, B)$ carbides in a martensite matrix. The addition of nickel promotes the formation of austenite dendrites as well as changes the morphology of the eutectic colonies. As the nickel content increases from 2.75 to 3.83 wt-\% nickel, and to $4.64 \mathrm{wt}-\%$ nickel, the austenite is observed to develop from a scattered structure, to a dendritic structure, and finally a networked structure, respectively. The eutectic evolution is mainly due to the change in the leading phase from eutectic carbide to austenite owing to the addition of nickel.

2. The hardness of hardfacing alloys decreases from $64.2 \mathrm{HRC}$ with no nickel addition to $58.2 \mathrm{HRC}$ with 4.64 wt-\% nickel addition.

3. The wear loss and the final friction coefficient of the hardfacing alloy decreases with increasing the content of nickel to 2.75 wt- $\%$ and then increases with further increase in the nickel content in the hardfacing alloy.

4. The morphology of the worn surfaces of the hardfacing alloys shows several cracks for the hardfacing alloys with 0.13 wt-\% nickel, retains a smooth texture for the hardfacing alloy with 2.75 wt-\% nickel, and exhibits extensive plastic deformation and grooving as the nickel content is further increased.

5 . The hardfacing alloy with $2.75 \mathrm{wt}-\%$ nickel has the optimum wear resistance and cracking resistance owing to the presence of the higher fraction of martensite in the matrix and 


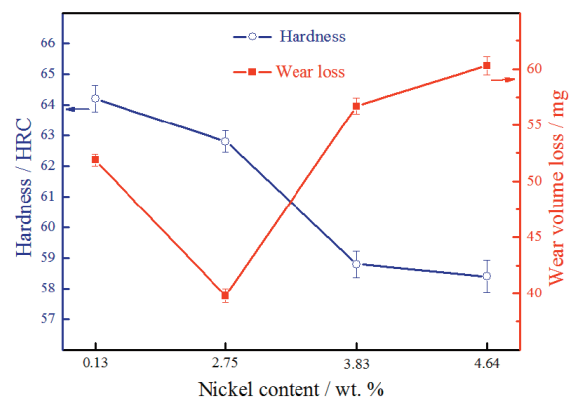

Fig. 8 - Hardness and wear loss of hardfacing alloys with different nickel levels.
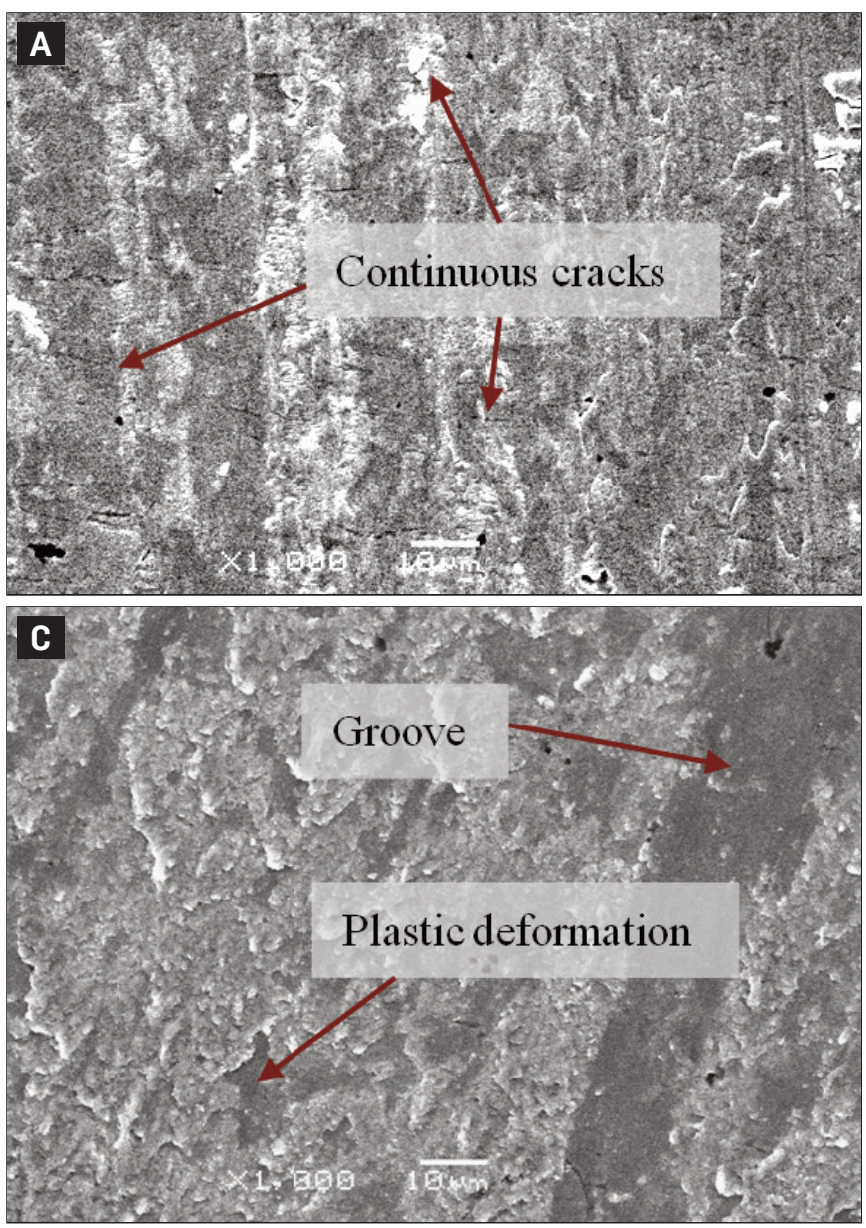

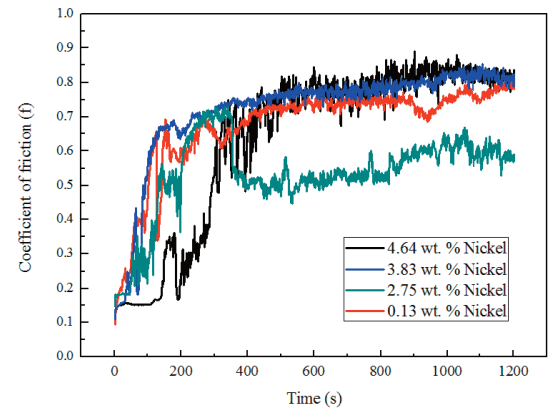

Fig. 9 - Friction coefficients of hardfacing alloys with different nickel levels.
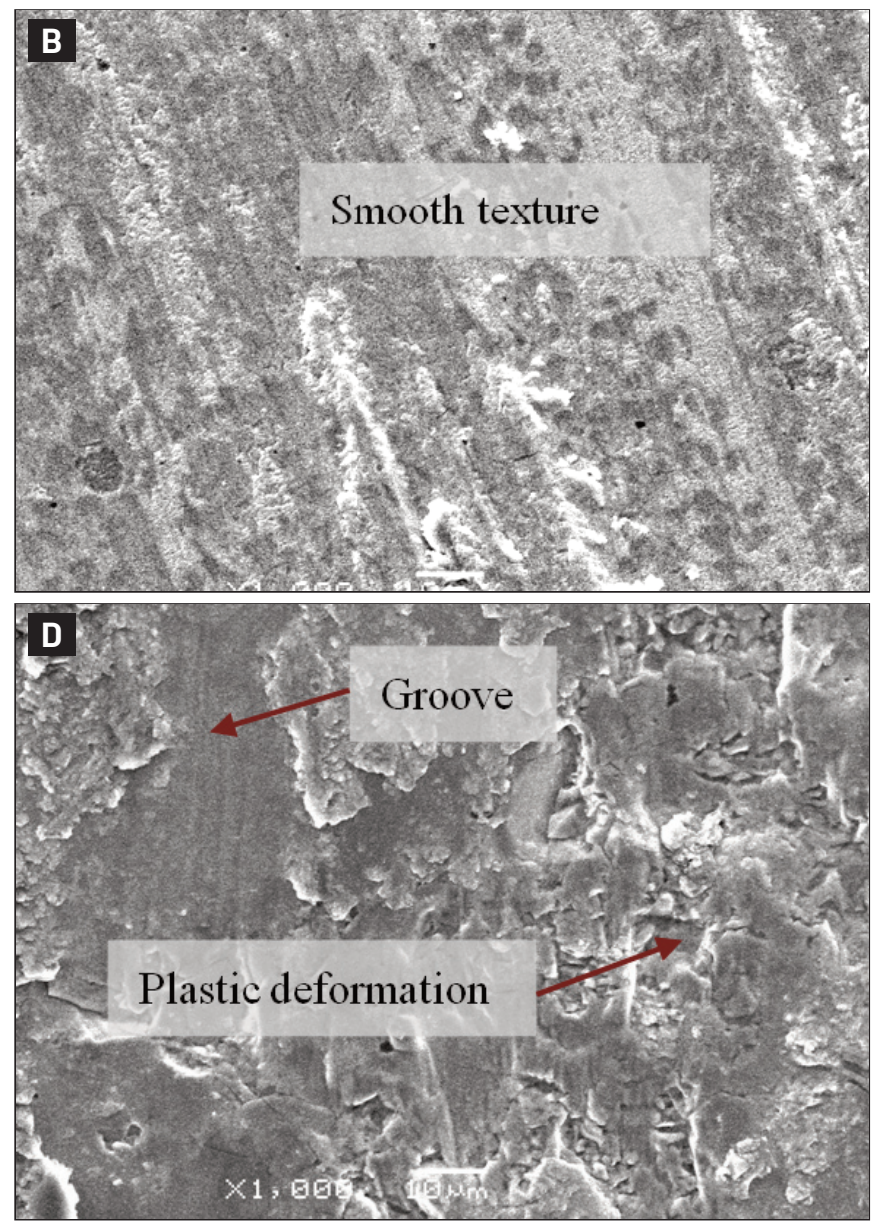

Fig. 10 - SEM image of worn surfaces of hardfacing alloys with different nickel levels.

optimum amount of retained austenite needed to provide the crack resistance.

\section{Acknowledgments}

This work was supported in part by funding from the National Natural Science Foundation of China (Grant No. 51405208), the China Postdoctoral Science Foundation funded project (Grant No. 2016M601753), the Natural Science Foundation of the Jiangsu Higher Education Institutions of
China (Grant No. 16KJB460007), the Jiangsu Government Scholarship for Overseas Studies (Grant No. JS-2016-133), and the Priority Academic Program Development of Jiangsu Higher Education Institutions.

\section{References}

1. Liu, D. S., and Wei, P. 2015. Properties of silicon-added, ironbased, slag-free, self-shielded flux-cored wire. Welding Journal 94(11): 351-s to 357-s.

2. Lai, H. H., Hsieh, C. C., Lin, C. M., and Wu, W. 2017. Character- 


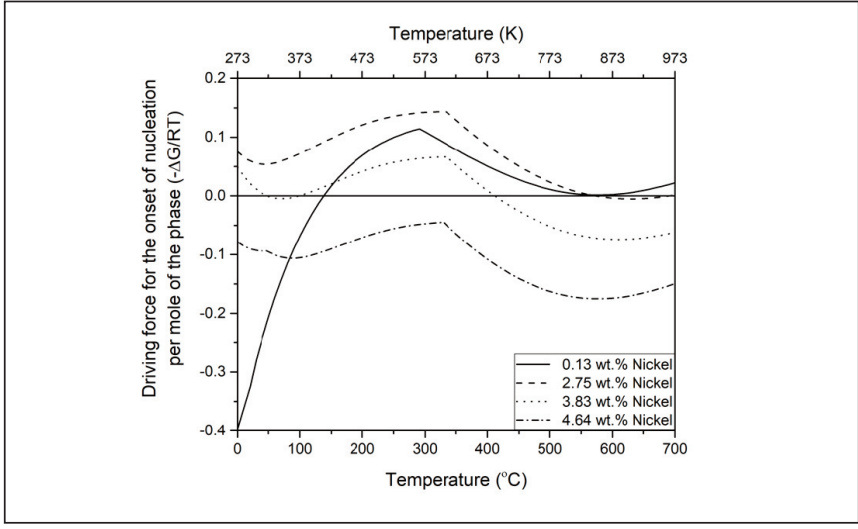

Fig. 11 - Driving force for nucleation of ferrite from austenite derived from ThermoCalc. The driving forces displayed are divided by radiographic testing; hence, the $y$-axis is dimensionless.

istics of eutectic $\alpha(\mathrm{Cr}, \mathrm{Fe})-(\mathrm{Cr}, \mathrm{Fe})_{23} \mathrm{C}_{6}$ in the eutectic $\mathrm{Fe}-\mathrm{Cr}-\mathrm{C}$ hardfacing alloy. Metallurgical \& Materials Transactions A 48(1): 493-500. DOI: 10.1007/s11661-016-3828-5

3. Yang, K., Gao, Y., Yang, K., Bao, Y., and Jiang, Y. 2017. Microstructure and wear resistance of Fe-Cr13-C-Nb hardfacing alloy with Ti addition. Wear 376-377, Part B: 1091-1096. DOI: 10.1016/j.wear.2016.12.062

4. Singla, Y. K., Arora, N., and Dwivedi, D. K. 2017. Dry sliding adhesive wear characteristics of Fe-based hardfacing alloys with different $\mathrm{CeO}_{2}$ additives - A statistical analysis. Tribology International 105: 229-240. DOI: 10.1016/j.triboint.2016.10.015

5. Rauta, R. P., Rodrigues, S. F., Leal, V. S., Rels, G. S, Aranas Jr., C., and Ferraresi, V. A. 2016. Influence of pushing and pulling the electrode procedure and addition of second layer of welding on the wear in hardfacing of Fe-Cr-C. Materials Research 19(5): 1193-1200. DOI: 10.1590/1980-5373-MR-2016-0230

6. Coronado, J. J. 2011. Effect of load and carbide orientation on abrasive wear resistance of white cast iron. Wear 270(11): 823-827. DOI: 10.1016/j.wear.2011.02.009

7. Yang, J., Tian J., Hao F., Dan, T., Ren, X., Yang, Y., and Yang, Q. 2014. Microstructure and wear resistance of the hypereutectic $\mathrm{Fe}-\mathrm{Cr}-$ $\mathrm{C}$ alloy hardfacing metals with different $\mathrm{La}_{2} \mathrm{O}_{3}$ additives. Applied Surface Science 289: 437-444. DOI: 10.1016/j.apsusc.2013.10.186

8. Liu, D. S., Liu, R. P., and Wei, Y. H. 2014. Influence of tungsten on microstructure and wear resistance of iron base hardfacing alloy. Materials Science \& Technology 30(3): 316-322. DOI: 10.1179/ 1743284713Y.0000000359

9. Liu, D., Liu, R., We, Y., Ma, Y., and Zhu, K. 2013. Microstructure and wear properties of $\mathrm{Fe}-15 \mathrm{Cr}-2.5 \mathrm{Ti}-2 \mathrm{C}-\mathrm{xB}$ wt.\% hardfacing alloys. Applied Surface Science 271: 253-259. DOI: 10.1016/ j.apsusc.2013.01.169

10. Correa, E. O., Alcântara, N. G., Valeriano, L. C., Barbedo, N. D., and Chaves, R. R. 2015. The effect of microstructure on abrasive wear of a Fe-Cr-C-Nb hardfacing alloy deposited by the open arc welding process. Surface \& Coatings Technology 276: 479-484. DOI: 10.1016/j.surfcoat.2015.06.026

11. Nikola, B., Darko, B., Darko, V., Marko, R., and Zoran, J. 2014. The advantages of using activated flux-cored wire compared to solid wire in the MAG welding process from the aspect of metallurgical characteristics. Metalurgija 53(3): 361-364. ISSN: 0543-5846
12. Liu, H. N., Nomura, M., Ogi, K., and Sakamoto, M. 2001. Abrasion resistance of high $\mathrm{Cr}$ cast irons at an elevated temperature. Wear 250(1): 71-75. DOI: 10.1016/S0043-1648(01)00665-2

13. Liu, D., Liu, R., and Wei, Y. 2012. Effects of titanium additive on microstructure and wear performance of iron-based slag-free selfshielded flux-cored wire. Surface \& Coatings Technology 207: 579-586. DOI: 10.1016/j.surfcoat.2012.07.078

14. Liu, S., Zhang, J., Wang, Z., Shi, Z., Zhou, Y., Ren, X., and Yang, $X$. 2017. Refinement and homogenization of $M_{7} C_{3}$ carbide in hypereutectic $\mathrm{Fe}-\mathrm{Cr}-\mathrm{C}$ coating by $\mathrm{Y}_{2} \mathrm{O}_{3}$ and TiC. Materials Characterization 132: 41-45. DOI: 10.1016/j.matchar.2017.08.004

15. Gualco, A., Svoboda, H. G., and Surian, E. S. 2016. Effect of welding parameters on microstructure of Fe-based nanostructured weld overlay deposited through FCAW-S. Welding International 30(8): 573-580. DOI: 10.1080/09507116.2015.1096533

16. Patrick, C. W., and Newell, W. F. July 20-24, 2014. Understanding welding cost: Using flux-cored arc welding (FCAW) for cost reduction and productivity improvement. ASME 2014 Pressure Vessels and Piping Conference. American Society of Mechanical Engineers. DOI: 10.1115/PVP2014-28084

17. Liu, D. S., Wei, Y. H., and Liu, R. P. 2015. Microstructure and wear mechanism change by $\mathrm{Nb}$ added in slag free self-shielded flux cored wire. Science \& Technology of Welding \& Joining 20(8): 693-701. DOI: 10.1179/1362171815Y.0000000056

18. Chatterjee, S., and Pal, T. K. 2003. Wear behaviour of hardfacing deposits on cast iron. Wear 255(1): 417-425. DOI: 10.1016/ S0043-1648(03)00101-7

19. Correa, E. O., Alcântara, N. G., Tecco, D. G., and Kumar, R. V. 2007. The relationship between the microstructure and abrasive resistance of a hardfacing alloy in the $\mathrm{Fe}-\mathrm{Cr}-\mathrm{C}-\mathrm{Nb}-\mathrm{V}$ system. Metallurgical \& Materials Transactions A 38(8): 1671-1680. DOI:

10.1007/s11661-007-9220-8

20. Yamamoto, K., Hashimoto, M., Sasaguri, N., and Matsubara, Y. 2009. Solidification of high chromium cast iron substituted by 25 to 70 mass\% Ni for Fe. Materials Transactions 50(9): 2253-2258. DOI 10.2320/matertrans.F-M2009818

21. Lin, C. M., Chang, C. M., Chen, J. H., and Wu, W. 2010. The effects of additive elements on the microstructure characteristics and mechanical properties of $\mathrm{Cr}$-Fe-C hard-facing alloys. Journal of Alloys \& Compounds 498(1): 30-36. DOI: 10.1016/j.jallcom. 2010. 03.127

22. Balachandran, G., Vadiraj, A., Kamaraj, M., and Kazuya, E. 2011. Mechanical and wear behavior of alloyed gray cast iron in the quenched and tempered and austempered conditions. Materials \& Design 32(7): 4042-4049. DOI: 10.1016/j.matdes.2011.03.054

23. Doebelin, N., and Kleeberg, R. 2015. Profex: A graphical user interface for the Rietveld refinement program BGMN. Journal of Applied Crystallography 48(5): 1573-1580. DOI: 10.1107/ S1600576715014685

24. Andersson, J. O., Helander, T., Höglund, L., Shi, P., and Sundman, B. 2002. Thermo-Calc \& DICTRA, computational tools for materials science. Calphad 26(2): 273-312. DOI: 10.1016/ S03645916(02)00037-8

25. Barnes, N., Clark, S., Seetharaman, S., and Mendez, P. F. 2018. Growth mechanism of primary needles during the solidification of chromium carbide overlays. Acta Materialia 151: 356-365. DOI: 10.1016/j.actamat.2018.03.050

26. Barnes, N., Borle, S., and Mendez, P. F. 2017. Large anomalous features in the microstructure of chromium carbide weld overlays. Science \& Technology of Welding \& Joining 22(7): 595-600. DOI: 10.1080/13621718.2017.1278831

DASHUANG LIU and MINGFANG WU are with the School of Material Science and Engineering, Jiangsu University of Science and Technology, Zhenjiang, China. LIU, LEIJUN LI (leijun@ualberta.ca), NEIL E. ANDERSON, and RANGASAYEE KANNAN are with the Department of Chemical \& Materials Engineering, University of Alberta, Edmonton, Canada. LIU and WEIMIN LONG are with the Zhengzhou Research Institute of Mechanical Engineering Co. Ltd., Zhengzhou, China. PING WEI is with the School of Naval Architecture \& Ocean Engineering, Jiangsu University of Science and Technology, Zhenjiang, China. 